\title{
Post-peroral endoscopic myotomy dehiscence treated with an esophageal fully covered self-expandable metal stent
}

Peroral endoscopic myotomy (POEM) is an effective and safe technique for treating esophageal achalasia [1-2]. Adverse events related to POEM, although uncommon, may present a diagnostic and therapeutic challenge [2-3]. Fully covered self-expandable metal stents (FCSEMSs) have been successfully used in several complications of esophageal procedures, such as perforation, fistula, and leakage [4-5].

A 59-year-old man presented with intermittent dysphagia to solids and fever. $\mathrm{He}$ had undergone POEM 6 days before for symptomatic type III achalasia (Eckardt's score of 8) with a posterior incision. Intravenous prophylactic antibiotics were administered before and after the procedure. Upper endoscopy (GIF-Q165; Olympus, Tokyo, Japan) revealed dehiscence of the previously closed mucosal incision, with purulent material located inside the tunnel ( $>$ Fig. 1, > Fig. 2). Gentamicin was flushed through the tunnel and intravenous antibiotics were started (piperacillin/tazobactam and metronidazole). A $23 \times 105-m m$ FCSEMS (Wallflex Esophageal Stent; Boston Scientific, Marlborough, Massachusetts, USA) was placed under direct endoscopic visualization (\$ Fig.3) and radioscopic control ( $\triangleright$ Video 1). The stent was repositioned using a rat tooth grasping forceps (FG48L-1; Olympus, Tokyo, Japan) and then fixed with a through-the-scope clip (Resolution 360 Clip; Boston Scientific) and an over-the-scope clip (OTSC System Set, $11 / 6 \mathrm{~mm}$, type t; Ovesco Endoscopy AG, Tuebingen, Germany). A thoracic computed tomography excluded mediastinitis, periesophageal fluid collections, or fistula. Antibiotics were continued for 14 days in association with fluconazole for 7 days. Afterwards, the patient showed clinical improvement. An upper endoscopy was performed 3 weeks weeks after stent deployment. The esophageal stent was re-

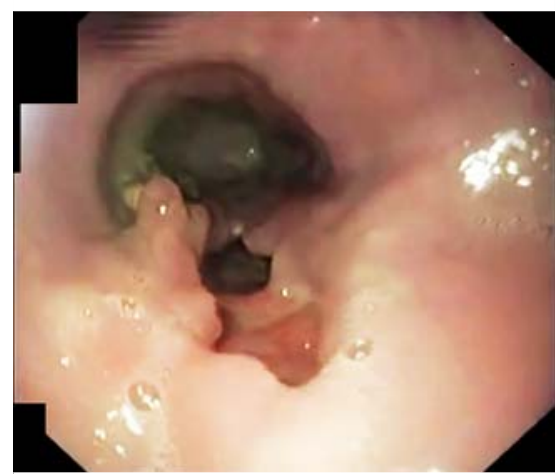

- Fig. 1 Upper endoscopy after peroral endoscopic myotomy showed dehiscence of the previously closed mucosal incision.

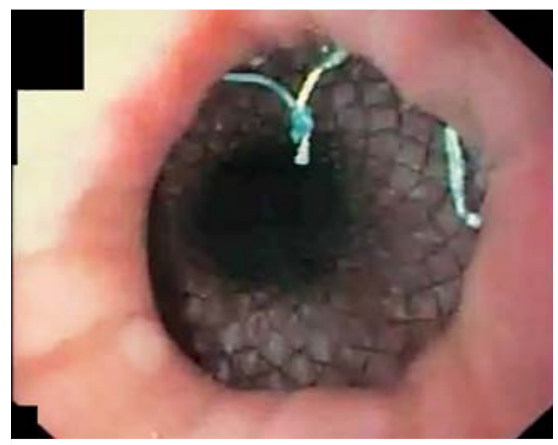

-Fig. 3 Endoscopic view after placement of fully covered self-expandable esophageal metal stent.

moved using a rat tooth grasping forceps (FG-48L-1, Olympus), and complete closure of the former dehiscence was observed (> Fig.4). There was no difficulty passing the endoscope through the esophagogastric junction.

Endoscopy_UCTN_Code_CPL_1 $\mathrm{AH} \_2 \mathrm{AH}$

\section{Competing interests}

The authors declare that they have no conflict of interest.

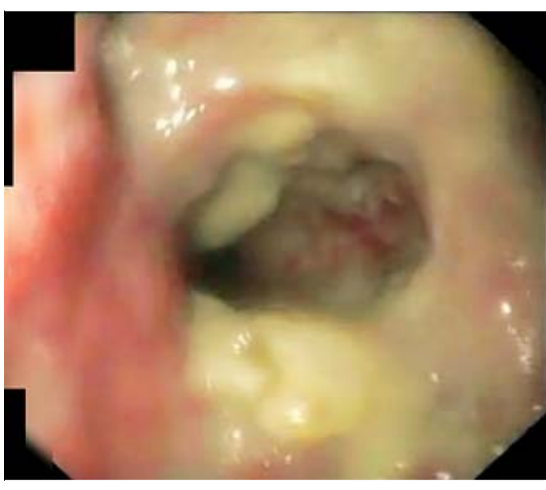

- Fig. 2 Endoscopic view of the inside of the tunnel containing purulent material.

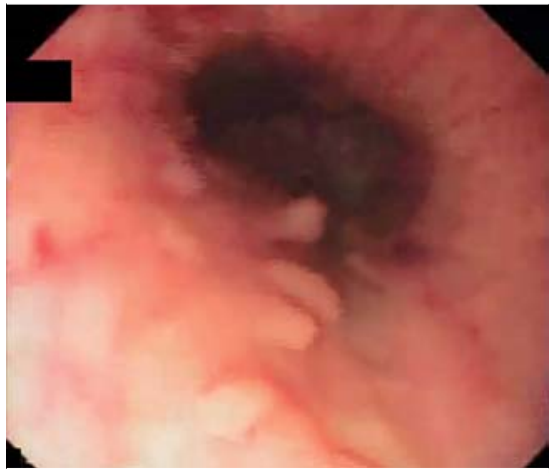

- Fig. 4 Endoscopic evaluation after stent removal showing closure of the dehiscence.

The authors

Margarida Flor de Lima, Nuno Nunes, Carolina Chálim Rebelo, Diogo Bernardo Moura, Ana Catarina Rego, Nuno Paz, Maria Antónia Duarte

Gastroenterology Department, Hospital do Divino Espírito Santo de Ponta Delgada, Ponta Delgada, Portugal 


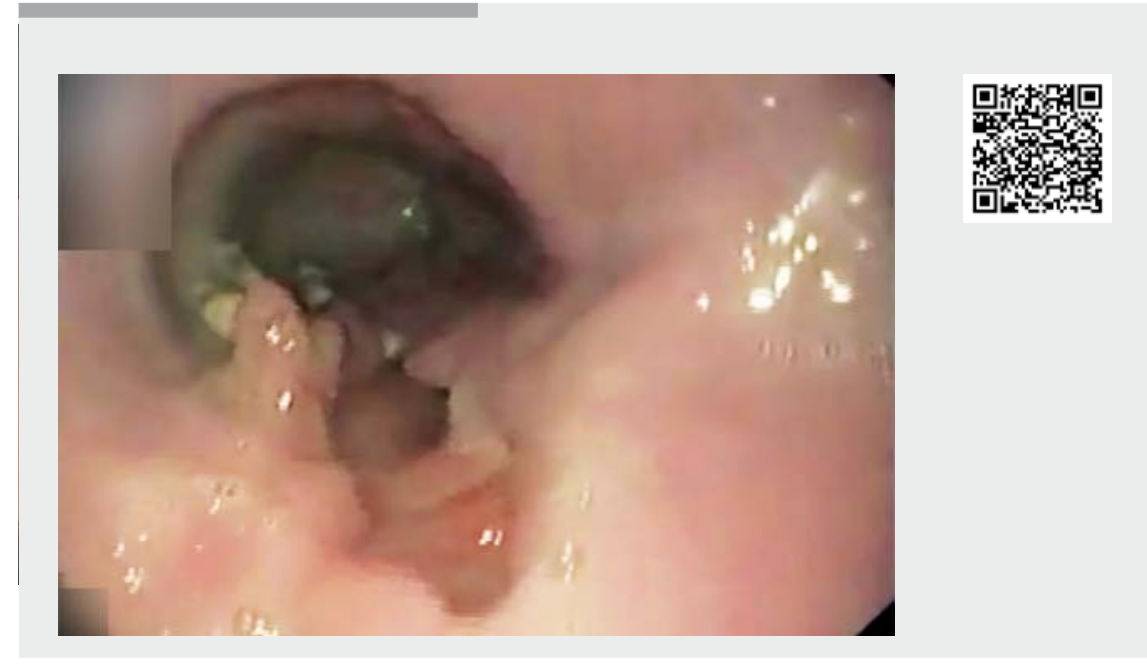

Video 1 An infected dehiscence of the mucosal incision after peroral endoscopic myotomy was closed using a fully covered self-expandable esophageal metal stent placed for 3 weeks.

\section{Corresponding author}

\section{Margarida Flor de Lima}

Gastroenterology Department, Hospital do Divino Espírito Santo de Ponta Delgada,

Avenida D. Manuel I, Matriz, 9500-370

Ponta Delgada, Portugal

Fax: +351296203090

margaridaflordelima@hotmail.com

\section{References}

[1] Inoue H, Minami H, Kobayashi Y et al. Peroral endoscopic myotomy (POEM) for esophageal achalasia. Endoscopy 2010; 42: 265271

[2] Zhang XC, Li QL, Xu MD et al. Major perioperative adverse events of peroral endoscopic myotomy: a systematic 5-year analysis. Endoscopy 2016; 48: 967-978

[3] Nabi Z, Reddy DN, Ramchandani M. Adverse events during and after per-oral endoscopic myotomy: prevention, diagnosis, and management. Gastrointest Endosc 2018; 87: 417
[4] Fernández A, González-Carrera V, GonzálezPortela $C$ et al. Fully covered metal stents for the treatment of leaks after gastric and esophageal surgery. Rev Esp Enferm Dig 2015; 107: 608-613

[5] van Boeckel PG, Sijbring A, Vleggaar FP et al. Systematic review: temporary stent placement for benign rupture or anastomotic leak of the oesophagus. Aliment Pharmacol Ther 2011; 33: 1292-1301

Bibliography

\section{Endoscopy 2021; 53: E293-E294}

DOI 10.1055/a-1264-6842

ISSN 0013-726X

published online 8.10 .2020

(C) 2020. Thieme. All rights reserved.

Georg Thieme Verlag KG, Rüdigerstraße 14, 70469 Stuttgart, Germany

\section{ENDOSCOPY E-VIDEOS}

https://eref.thieme.de/e-videos

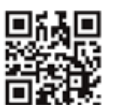

Endoscopy E-Videos is a free access online section, reporting on interesting cases and new techniques in gastroenterological endoscopy. All papers include a high quality video and all contributions are freely accessible online.

This section has its own submission website at https://mc.manuscriptcentral.com/e-videos 